\title{
Risk factors for postoperative CSF leakage after endonasal endoscopic skull base surgery: a meta-analysis and
} systematic review*

\author{
Jong Seung Kim ${ }^{1,2,3}$, Sang Duk Hong ${ }^{4}$ \\ Department of Medical Informatics, College of Medicine, Jeonbuk National University, Jeonju, Republic of Korea \\ 2 Department of Otorhinolaryngology-Head and Neck Surgery, College of Medicine, Jeonbuk National University, Jeonju, \\ Republic of Korea \\ ${ }^{3}$ Research Institute of Clinical Medicine of Jeonbuk National University - Biomedical Research Institute of Jeonbuk National \\ University Hospital, Jeonju, Republic of Korea \\ ${ }^{4}$ Department of Otorhinolaryngology-Head and Neck Surgery, Samsung Medical Center, Sungkyunkwan University School \\ of Medicine, Seoul, Republic of Korea
}

Rhinology 59: 1, 10 - 19, 2021

*Received for publication:

April 11, 2020

Accepted: June 26, 2020

\begin{abstract}
Background: Cerebrospinal fluid (CSF) leakage is a complication that any surgeon working in the field of skull base surgery does not wish to encounter. The surgical approach to the skull base often varies, and the various sizes and locations of skull base lesions make it difficult to determine the cause of CSF leakage. However, it is useful to investigate which factors contribute to postoperative CSF leakage.
\end{abstract}

Methods: Related studies were identified by searching the following databases: PubMed/Medline, Embase, and Web of Sciences through December 2019. Random-effects models were used to calculate odds ratios (ORs) and 95\% confidence intervals (Cls). The Newcastle-Ottawa scale was used to evaluate the quality of observational studies.

Results: Our search yielded 56 retrospective cohort studies involving a total of 11,826 skull base surgical procedures. The overall rate of postoperative CSF leakage was $7.2 \%$. The effect of obesity on postoperative CSF leakage had an OR of 1.88 , and the effect of perioperative radiotherapy on postoperative CSF leakage yielded an OR of 1.87. High intraoperative CSF flow rate also had a significant OR of 2.98. On the other hand, a pedicled vascularized flap efficiently reduced the risk of postoperative CSF leakage. Defect size and the presence or absence of a lumbar drain had no effect on postoperative CSF leakage.

Conclusions: This comprehensive quantitative assessment of postoperative CSF leakage showed that obesity, perioperative radiotherapy, and high intraoperative CSF flow rate raised the risk of CSF leakage; however, a pedicled vascularized flap can effectively reduce the risk of postoperative CSF leakage.

\section{Level of Evidence: level NA}

Key words: cerebrospinal fluid leakage, skull base, obese; radiotherapy, vascularized flap

\section{Introduction}

The endoscope was first introduced into the field of sinus surgery in the late 1980s, but the application of this instrument in skull base surgery has been relatively recent ${ }^{(1)}$. The greatest advantage of this technique over transcranial surgery is that it does not lead to brain retraction, resulting in fewer complications and shorter hospital stays, which greatly improves patient quality of life ${ }^{(2)}$. However, the most significant criticism of endoscopic skull base surgery is the risk of cerebrospinal fluid (CSF) leakage and this remains a challenge for skull base surgeons. Understanding the risk factors for CSF leakage after endoscopic skull base surgery is important to surgeons. A high body mass index (BMI) could impair venous drainage because of increased intraabdominal and thoracic pressure, therefore, obesity 
is generally considered to be a risk factor for postoperative CSF leakage ${ }^{(3)}$. However, a recent study showed no correlation between obesity and the rate of CSF leakage ${ }^{(4)}$. A larger defect size induced more postoperative CSF leakage in one study ${ }^{(5)}$, whereas another study reported that there was no correlation between defect size and postoperative CSF leakage ${ }^{(6)}$. A lumbar drain can be applied to reduce postoperative CSF leakage, but its efficiency has been considered debatable among several studies ${ }^{(4,7,8)}$. Vascularized flaps, introduced to prevent skull base defects, are known to prevent significant postoperative CSF leakage; however, results of their ability to reduce postoperative CSF leakage are also discordant ${ }^{(9,10)}$.

These variable and inconclusive results might be the result of heterogenous inclusion criteria and small sample sizes. In addition, there is no comprehensive meta-analysis of the factors influencing CSF leakage after endoscopic skull base surgery. Therefore, we aimed to systematically review the potential risk factors such as radiation history, defect size, the presence of obesity, use of CSF diversion, or the application of vascularized flaps.

\section{Materials and methods}

\section{Search strategy}

Two investigators (JSK, SDH) independently searched all of the relevant studies published to November 2019 in the PubMed/ Medline, Embase, and Web of Science databases. The search details for PubMed/Medline were as follows: (("skull base"[MeSH Terms] OR ("skull"[All Fields] AND "base"[All Fields]) OR "skull base"[All Fields]) AND ("cerebrospinal fluid leak"[MeSH Terms] OR ("cerebrospinal"[All Fields] AND "fluid"[All Fields] AND "leak"[All Fields]) OR "cerebrospinal fluid leak"[All Fields])) AND (("surgical procedures, operative"[MeSH Terms] OR ("surgical"[All Fields] AND "procedures"[All Fields] AND "operative"[All Fields]) OR "operative surgical procedures"[All Fields] OR "operation"[All Fields]) OR ("reconstructive surgical procedures"[MeSH Terms] OR ("reconstructive"[All Fields] AND "surgical"[All Fields] AND "procedures"[All Fields]) OR "reconstructive surgical procedures"[All Fields] OR "reconstruction"[All Fields])). We used similar key terms to search the other databases.

\section{Selection of literature}

The definition of skull base surgery or reconstruction included the following conditions: skull base tumor, preoperative or intraoperative CSF leakage, and cystic lesions. Skull base tumors included craniopharyngioma, meningioma, pituitary adenoma, chordoma, neuroblastoma, germinoma, etc, and cystic lesions included arachnoid cyst, Rathke's cyst, and encephalocele. The inclusion criteria were as follows: 1) studies mentioning CSF leakage after skull base surgery or reconstruction; 2) studies including data on endonasal endoscopic surgery; 3) prospective or retrospective studies; 4) studies dealing with a human

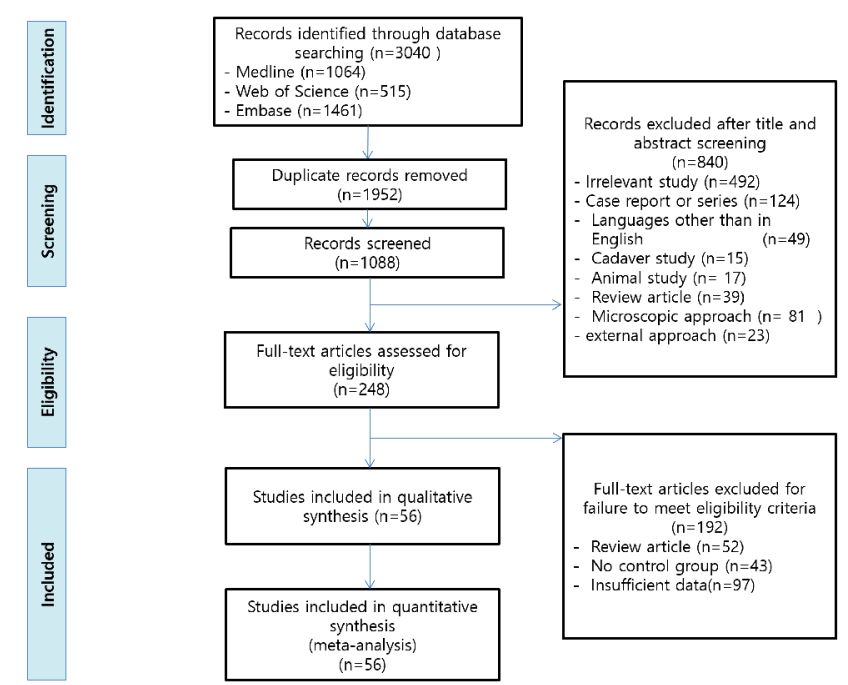

Figure 1. Flow chart for identification, screening, and eligibility of the studies included in this meta-analysis ( $\mathrm{n}=$ number of studies).

population.

The exclusion criteria were as follows: 1) spontaneous CSF leakage; 2 ) no data regarding CSF leakage; 3 ) language other than English; 4) review article; 5) case report; 6) cadaver or animal study; 7) skull base surgery through an external or microscopic approach; 8) studies without relevant data.

\section{Data extraction}

Relevant data were collected by the two authors independently. Any discrepancy between the two authors was discussed until agreement was reached. The following information was collected from each paper: publication year, author names, study setting, method of surgical approach, age, sex, body mass index, size of defect, CSF leakage flow rate, use of vascularized flap, presence or absence of a lumbar drain, and perioperative radiotherapy. High flow CSF leakage was taken to include those cases mentioned in the original article as having high flow as well as the following cases: 1) all craniopharyngioma; 2) tuberculum sella, planum or olfactory groove meningioma; 3 ) intradural clival chordoma. Pituitary adenoma was considered to be low flow unless otherwise noted. To minimize selection bias, we only analyzed the efficacy of vascularized flaps in patients with intraoperative CSF leakage. In the case of pituitary adenoma, intraoperative CSF leakage was rare, and vascularized flaps were rarely used, so these cases were excluded from the analysis of vascularized flaps.

\section{Methodological quality}

For non-randomized controlled trials, the Newcastle-Ottawa score was used to assess methodological quality. A maximum of 9 stars was attainable. The Cochrane risk of bias tool was applied to assess the quality of randomized controlled trials (RCT). 
A Study

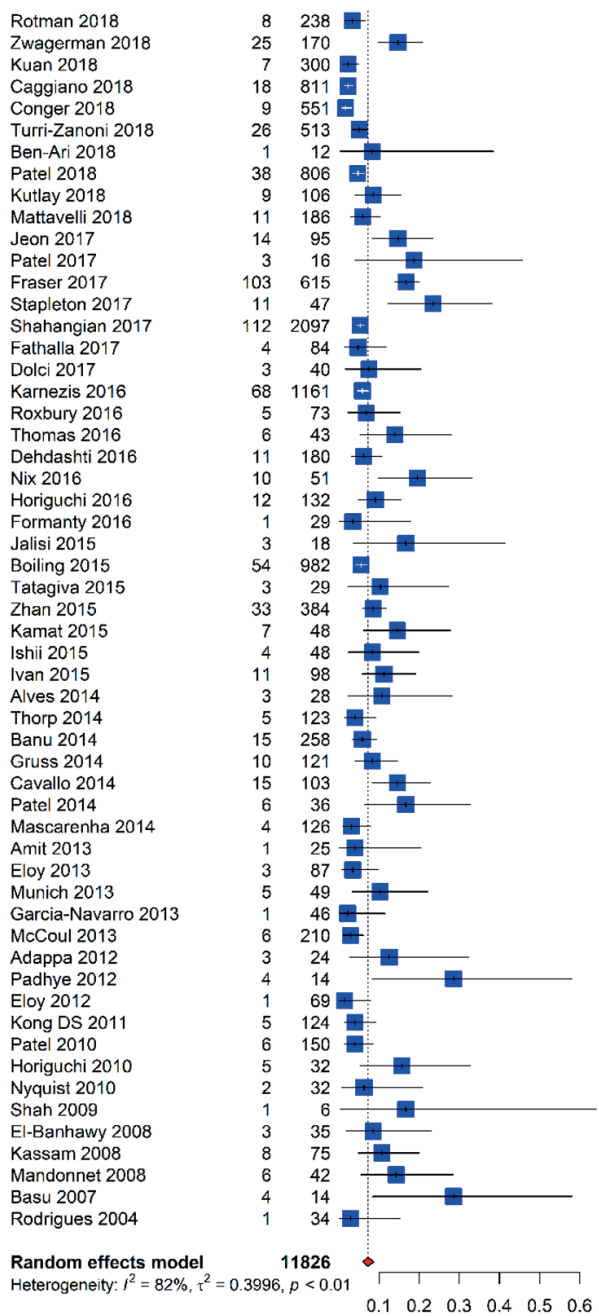

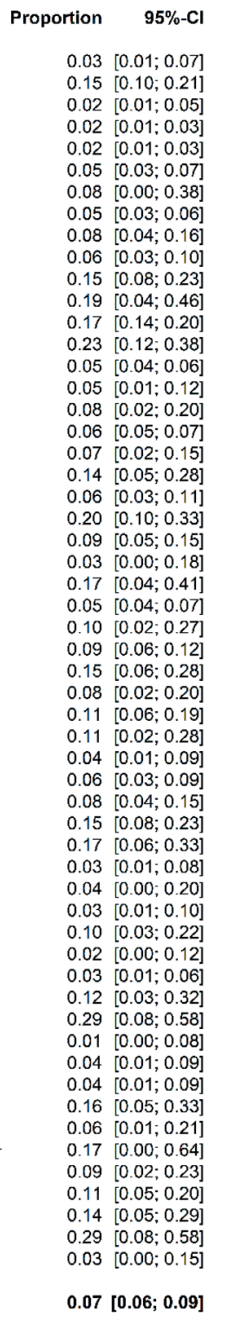

B Study

Omitting Rotman 2018

Omitting Z:Nagerman 2018

Oniiliting Kuan 2018

Omitting Caggiano 2018

Omitting Conger 2018
Omitting Turri-Zanoni 2018

Omitting Ben-Ari 2018

Omitting Patel 2018

Omitting Kutlay 2018
Omitting Mattavelli 2018

Omitting Jeon 2017

Omitting Patel 2017

Omitting F-aser 2017

Omitting Stapleton 2017

Omitting Fathalla 2017

Omitting Dolci 2017

Omitting Karnezis 2016

Omitting Karnezis 2016

Omitting Tromes 2016

Omitting Dehdashti 2016

Omilling Nix 2016

Omitting Horiguchi 2016

Omitting Jalisi 2015

Omitting Boiling 2015

Omitting Tatagiva 2015

Omitting Zาan 2015

Omitting Kamat 2015

Omitting Ishii 2015

Omitting Ivan 2015

Omitting Alves 2014

Omitting Tาorp 2014

Omitting Banu 2014

Omitting Gruse 2011

Omitting Cavallo 2014

Omitting Mascarenha 2014

Omitting Amit 2013

Omitting Eloy 2013

Omitting Munich 2013

Omitting Garcia-Navarro 2013

Omitting McCoul 2013

Omitting Adappa 2012

Omitting Padhye 20

Omiting Kong DS 2011

Omitting Patel 2010

Omitting Horiguchi 2010

Omiting Nyquist 2010

Omitting Shah 2009

Omitting El-Banhawy 2008

Omitting Kassam 2008

Omiting Mandonnet 2008

Omitting Basu 2007

Omitting Rodrigues 2004

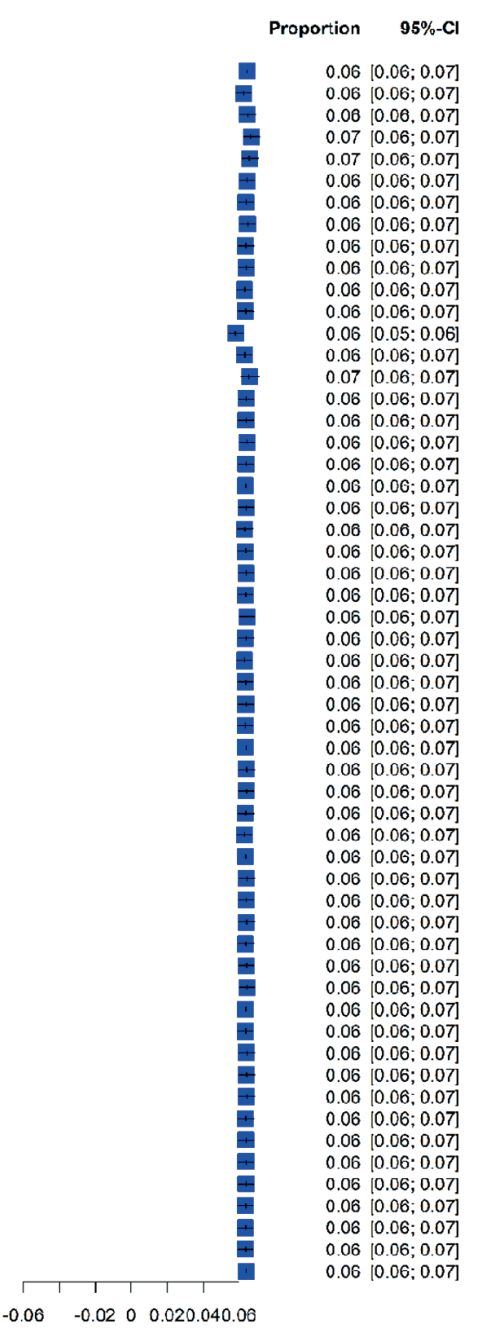

Figure 2. A) Forest plot of overall rate of CSF leakage after skull base surgery using single proportion analysis. B) Sensitivity analysis according to publication year.

\section{Statistics}

A meta-analysis of the selected studies was performed using R statistical software (R Foundation for Statistical Computing, Vienna, Austria). We also used Comprehensive Meta-Analysis software (version 2.0, Biostat Inc., Englewood, NJ, USA). Dichotomous variables were analyzed using the inverse variance method and a random effects model. This particular model was selected because it considers heterogeneity among studies with regard to different clinical environments or methodologies, and thus enables a more strict and detailed analysis than the fixed effects model.

We used the PRISMA methodologies ${ }^{(11)}$. The $\mathrm{I}^{2}$-statistic was used to assess heterogeneity across the studies. An $\mathrm{I}^{2}$ value of $0 \%$ indicated no heterogeneity, while values less than $50 \%$ indicated low heterogeneity, values less than $75 \%$ indicated moderate heterogeneity and values above $75 \%$ indicated substantial heterogeneity. Egger's test and funnel plots were used to view the publication bias ${ }^{(12)}$.

We calculated the odds ratio (OR) with 95\% confidence intervals (Cls) for dichotomous variables, and finally performed pooled analyses with $\mathrm{R}$ statistical software. All authors were qualified to combine and analyze data. Ethics committee or institutional review board approval was not required for systematic reviews and meta-analysis.

The Duval and Tweedie trim and fill method was used as a method to adjust the effect size, assuming that unpublished missing studies were published ${ }^{(13)}$.

\section{Results}

\section{Literature retrieval}

A PRISMA reporting diagram of the study selection process and the main reasons for exclusion can be found in Figure 1. A total of 3,040 articles were identified from the PubMed/Medline, Embase and Web of Science databases. We removed 1,952 
Table 1. Characteristics of the 56 studies included in this meta-analysis.

\begin{tabular}{|c|c|c|c|c|c|c|c|}
\hline $\begin{array}{l}\text { Publi- } \\
\text { cation } \\
\text { year }\end{array}$ & $\begin{array}{l}\text { First author and } \\
\text { reference }\end{array}$ & $\begin{array}{l}\text { Primary } \\
\text { outcome }\end{array}$ & Methodology & $\begin{array}{c}\text { Newcastle- } \\
\text { Ottawa Scale Or } \\
\text { Cochrane Risk Of } \\
\text { Bias tool }\end{array}$ & $\begin{array}{l}\text { No. of cases } \\
\text { with postop } \\
\text { CSF leakage }\end{array}$ & $\begin{array}{l}\text { Total no. of } \\
\text { patients }\end{array}$ & $\begin{array}{l}\text { Follow-up } \\
\text { (years) }\end{array}$ \\
\hline 2018 & Rotman $^{(14)}$ & Flap & Retrospective & 7 & 8 & 238 & 2009-2017 \\
\hline 2018 & Zwagerman ${ }^{(4)}$ & LD & $\mathrm{RCT}$ & Low & 25 & 170 & 2011-2015 \\
\hline 2018 & Kuan ${ }^{(15)}$ & Flap & Retrospective & 6 & 7 & 300 & 2013-2016 \\
\hline 2018 & Caggiano ${ }^{(16)}$ & Obesity, LD, RTx & Retrospective & 8 & 18 & 811 & $2008-2017$ \\
\hline 2018 & Conger ${ }^{(10)}$ & Flap & Retrospective & 7 & 9 & 551 & 2010-2017 \\
\hline 2018 & Turri-Zanoni ${ }^{(6)}$ & Flap, RTx, size & Retrospective & 9 & 26 & 513 & 1998-2017 \\
\hline 2018 & Ben-Ari ${ }^{(17)}$ & LD, sella & Retrospective & 7 & 1 & 12 & 2011-2016 \\
\hline 2018 & Patel ${ }^{(18)}$ & Flap, RTx & Retrospective & 8 & 38 & 806 & 2004-2016 \\
\hline 2018 & Kutlay ${ }^{(19)}$ & $\mathrm{TC}$ & Retrospective & 5 & 9 & 106 & 2010-2017 \\
\hline 2018 & Mattavelli ${ }^{(20)}$ & RTx & Retrospective & 9 & 11 & 186 & 2007-2015 \\
\hline 2017 & Jeon ${ }^{(21)}$ & Flap, TC & Retrospective & 8 & 14 & 95 & 2009-2014 \\
\hline 2017 & Patel (22) & Obesity, flap & Retrospective & 7 & 3 & 16 & 1995-2016 \\
\hline 2017 & Fraser ${ }^{(3)}$ & Obesity, flap, LD, & Retrospective & 8 & 103 & 615 & 1997-2012 \\
\hline 2017 & Stapleton ${ }^{(9)}$ & Obesity, flap, sella, TC & Retrospective & 7 & 11 & 47 & 1999-2014 \\
\hline 2017 & Shahangian ${ }^{(23)}$ & Flap, LD, RTx & $\begin{array}{l}\text { Retrospective, } \\
\text { multicenter }\end{array}$ & 9 & 112 & 2097 & 2002-2014 \\
\hline 2017 & Fathalla ${ }^{(24)}$ & Size, sella, TC, FR & Retrospective & 7 & 4 & 84 & 1999-2014 \\
\hline 2017 & Dolci (25) & $\mathrm{FR}$, sella & Retrospective & 7 & 3 & 40 & 2012-2014 \\
\hline 2016 & Karnezis ${ }^{(26)}$ & Flap, LD, RTx, sella, FR & Retrospective & 8 & 68 & 1161 & $2002-2014$ \\
\hline 2016 & Roxbury ${ }^{(27)}$ & Obesity, FR & Retrospective & 6 & 5 & 73 & 2008-2014 \\
\hline 2016 & Thomas ${ }^{(28)}$ & FR, sella & Retrospective & 7 & 6 & 43 & 2011-2015 \\
\hline 2016 & Dehdashti ${ }^{(29)}$ & $\mathrm{FR}$ & Retrospective & 8 & 11 & 180 & 2009-2013 \\
\hline 2016 & $\mathrm{Nix}^{(30)}$ & FR, sella, TC & Retrospective & 8 & 10 & 51 & 2009-2015 \\
\hline 2016 & Horiguchi ${ }^{(31)}$ & Flap & Retrospective & 9 & 12 & 132 & 1990-2014 \\
\hline 2016 & Formanty ${ }^{1302}$ & $\mathrm{RTx}$ & Retrospective & 8 & 1 & 29 & 2009-2014 \\
\hline 2015 & Jalisi ${ }^{(5)}$ & Flap, LD, size & Retrospective & 8 & 3 & 18 & $2005-2008$ \\
\hline 2015 & Boiling ${ }^{(33)}$ & Obesity & $\begin{array}{l}\text { Retrospective } \\
\text { multicenter }\end{array}$ & 8 & 54 & 982 & 2002-2014 \\
\hline 2015 & Tatagiva ${ }^{(34)}$ & Size & Retrospective & 7 & 3 & 29 & $2005-2013$ \\
\hline 2015 & Zhan (35) & LD & Retrospective & 7 & 33 & 384 & 2012-2014 \\
\hline 2015 & Kamat ${ }^{(36)}$ & FR, LD, TC & Retrospective & 7 & 7 & 48 & 2008-2012 \\
\hline 2015 & Ishii ${ }^{(37)}$ & FR, flap, sella, TC & Retrospective & 6 & 4 & 48 & $2001-2014$ \\
\hline 2015 & $\operatorname{Ivan}{ }^{(2)}$ & Obesity, flap, RTx & Retrospective & 8 & 11 & 98 & 2008-2012 \\
\hline 2014 & Alves ${ }^{(38)}$ & RTx & Retrospective & 7 & 3 & 28 & 1992-2011 \\
\hline 2014 & Thorp ${ }^{(39)}$ & FR, RTx, sella, TC & Retrospective & 6 & 5 & 123 & NA \\
\hline 2014 & Banu ${ }^{(40)}$ & LD, sella, TC & Retrospective & 8 & 15 & 258 & 2003-2012 \\
\hline 2014 & Gruss ${ }^{(41)}$ & LD, RTx, size & Retrospective & 7 & 10 & 121 & $2005-2012$ \\
\hline 2014 & Cavallo ${ }^{(42)}$ & Flap, LD & Retrospective & 9 & 15 & 103 & 1997-2012 \\
\hline 2014 & Patel ${ }^{(43)}$ & LD, size & Retrospective & 8 & 6 & 36 & $2005-2010$ \\
\hline 2014 & Mascarenha ${ }^{(44)}$ & FR, Flap, sella, TC & Retrospective & 7 & 4 & 126 & 2004-2012 \\
\hline 2013 & Amit ${ }^{(45)}$ & Flap, RTx & Retrospective & 6 & 1 & 25 & 2008-2011 \\
\hline 2013 & Eloy ${ }^{(46)}$ & Sella, TC & Retrospective & 7 & 3 & 87 & 2008-2012 \\
\hline 2013 & Munich ${ }^{(47)}$ & FR, sella & Retrospective & 7 & 5 & 49 & NA \\
\hline 2013 & Garcia-Navarro ${ }^{(48)}$ & FR, LD, flap & Retrospective & 7 & 1 & 46 & 2005-2010 \\
\hline
\end{tabular}




\begin{tabular}{|c|c|c|c|c|c|c|c|}
\hline $\begin{array}{l}\text { Publi- } \\
\text { cation } \\
\text { year }\end{array}$ & $\begin{array}{l}\text { First author and } \\
\text { reference }\end{array}$ & $\begin{array}{l}\text { Primary } \\
\text { outcome }\end{array}$ & Methodology & $\begin{array}{c}\text { Newcastle- } \\
\text { Ottawa Scale Or } \\
\text { Cochrane Risk Of } \\
\text { Bias tool }\end{array}$ & $\begin{array}{l}\text { No. of cases } \\
\text { with postop } \\
\text { CSF leakage }\end{array}$ & $\begin{array}{l}\text { Total no. of } \\
\text { patients }\end{array}$ & $\begin{array}{l}\text { Follow-up } \\
\text { (years) }\end{array}$ \\
\hline 2013 & McCoul (48) & Flap & Retrospective & 8 & 6 & 210 & 2003-2011 \\
\hline 2012 & Adappa $^{(7)}$ & LD, size & Retrospective & 7 & 3 & 24 & 2008-2011 \\
\hline 2012 & Padhye ${ }^{(49)}$ & Size & Retrospective & 7 & 4 & 14 & 2004-2010 \\
\hline 2012 & Eloy ${ }^{(50)}$ & Sella, TC & Retrospective & 7 & 1 & 69 & 2008-2011 \\
\hline 2011 & Kong DS (51) & $F R$ & Retrospective & 8 & 5 & 124 & 2008-2009 \\
\hline 2010 & Patel ${ }^{(52)}$ & FR, TC, sella & Retrospective & 6 & 6 & 150 & 2007-2008 \\
\hline 2010 & Horiguchi ${ }^{(53)}$ & Flap & Retrospective & 8 & 5 & 32 & 2005-2009 \\
\hline 2010 & Nyquist ${ }^{(54)}$ & Obesity & Retrospective & 7 & 2 & 32 & 2004-2009 \\
\hline 2009 & Shah ${ }^{(55)}$ & $F R$, sella & Retrospective & 7 & 1 & 6 & $2007-2008$ \\
\hline 2008 & El-Banhawy ${ }^{(56)}$ & Sella & Retrospective & 8 & 3 & 35 & 1997-2006 \\
\hline 2008 & Kassam ${ }^{(57)}$ & FR, sella, TC & Retrospective & 8 & 8 & 75 & 2006-2007 \\
\hline 2008 & Mandonnet ${ }^{(58)}$ & $\mathrm{RTx}, \mathrm{TC}$ & Retrospective & 7 & 6 & 42 & 1992-2002 \\
\hline 2007 & Basu (59) & Obesity, sella, TC & Retrospective & 6 & 4 & 14 & 1996-2004 \\
\hline 2004 & Rodrigues ${ }^{(60)}$ & RTx & Retrospective & 7 & 1 & 34 & 1995-2000 \\
\hline
\end{tabular}

Flap: vascularized flap reconstruction; LD: lumbar drain; TC: transclival; sella, transsellar; RTx: radiotherapy; Size: defect size; FR: flow rate; RCT: randomized controlled trial; NA: not available; $\mathrm{N}$, number

duplicate papers and analyzed the titles and abstracts in the remaining 1,088 papers.

After screening the title with abstract and reviewing the full texts, we excluded 1,032 publications because they failed to meet our eligibility criteria. These articles were excluded because they were review articles $(n=91)$, insufficient data $(n=97)$, case reports $(n=124)$, language other than English $(n=49)$, cadaver studies ( $n=15)$, animal studies ( $n=17)$, microscopic approach $(n=81)$, external approach $(n=23)$, irrelevant studies $(n=492)$, and no control group $(n=43)$.

Thus, 56 articles were included in our quantitative analysis and the characteristics of the 56 studies are summarized in Table 1 $(2,4-10,14-61)$. The study populations in the studies included did not overlap. For all analyses, a random effects model was used to evaluate the variation among and within the studies.

\section{Overall postoperative CSF leakage}

In a total of 56 studies, 753 out of 11,826 patients had CSF leakage after skull base surgery. The overall rate of postoperative CSF leakage was $7.2 \%$ [95\% Cl: 5.9-8.7\%, 12=82.3\%] (Figure 2A). In a sensitivity analysis, the rate of postoperative CSF leakage did not change in relation to the publication year (Figure 2B).

\section{Obesity}

Seven studies concerning obesity and comprising a total sample of 1,687 patients were included. We defined overweight as BMI over 25 and obese as BMI over 30. Analysis of postoperative CSF leakages across overweight and obesity revealed an odds ratio of 1.88 [ $95 \% \mathrm{Cl}, 1.35$ to $2.63, \mathrm{p}<0.01]$ with no heterogeneity
(I2=0\%) (Figure 3A). Egger's regression test was not performed due to the low sample size. In a funnel plot of obesity in relation to CSF leakage, the studies were spread at the top and center of the plot, which indicated no publication bias (Figure 4A). Using Duval and Tweedie's trim and fill to adjust for potentially unpublished reports revealed no change in the pooled OR (Figure 4B) (OR: 1.88 [95\% Cl, 1.34 to $2.63, \mathrm{p}<0.01]$. In a subgroup analysis, in an obese group in whom the BMI was over 30, the OR was 1.90 [95\% $\mathrm{Cl}, 1.22$ to $2.97, \mathrm{p}<0.01$ ] (Figure $3 \mathrm{~B}$ ).

Reconstruction method: vascularized flap vs. free graft Sixteen studies were included which examined the reconstruction method after tumor resection with a total sample of 3,579 patients. Analysis of CSF leakage across pedicled vascularized flap revealed an odds ratio of 0.62 [95\% Cl, 0.46 to $0.85, \mathrm{p}<0.01]$ with low heterogeneity (I2=9\%) (Figure $3 C$ ). Egger's regression test showed significant publication bias $(p<0.10)$. In a funnel plot of reconstruction method in relation to CSF leakage, the studies were spread at the center of the plot, which indicates low publication bias (Figure 4C). Using Duval and Tweedie's trim and fill to adjust for potentially unpublished reports revealed a significant change in the pooled OR (Figure 4D) (OR: 0.54 [95\% $\mathrm{Cl}, 0.37$ to $0.78, \mathrm{p}<0.01])$.

\section{Lumbar drain}

Fifteen studies concerning lumbar drains with a total sample of 2,604 patients were included in our study. Analysis of CSF leakage across lumbar drains revealed an odds ratio of 1.13 [95\% $\mathrm{Cl}, 0.73$ to $1.77, \mathrm{p}=0.41$ ] with moderate heterogeneity $(\mathrm{I} 2=51.1 \%)$ 


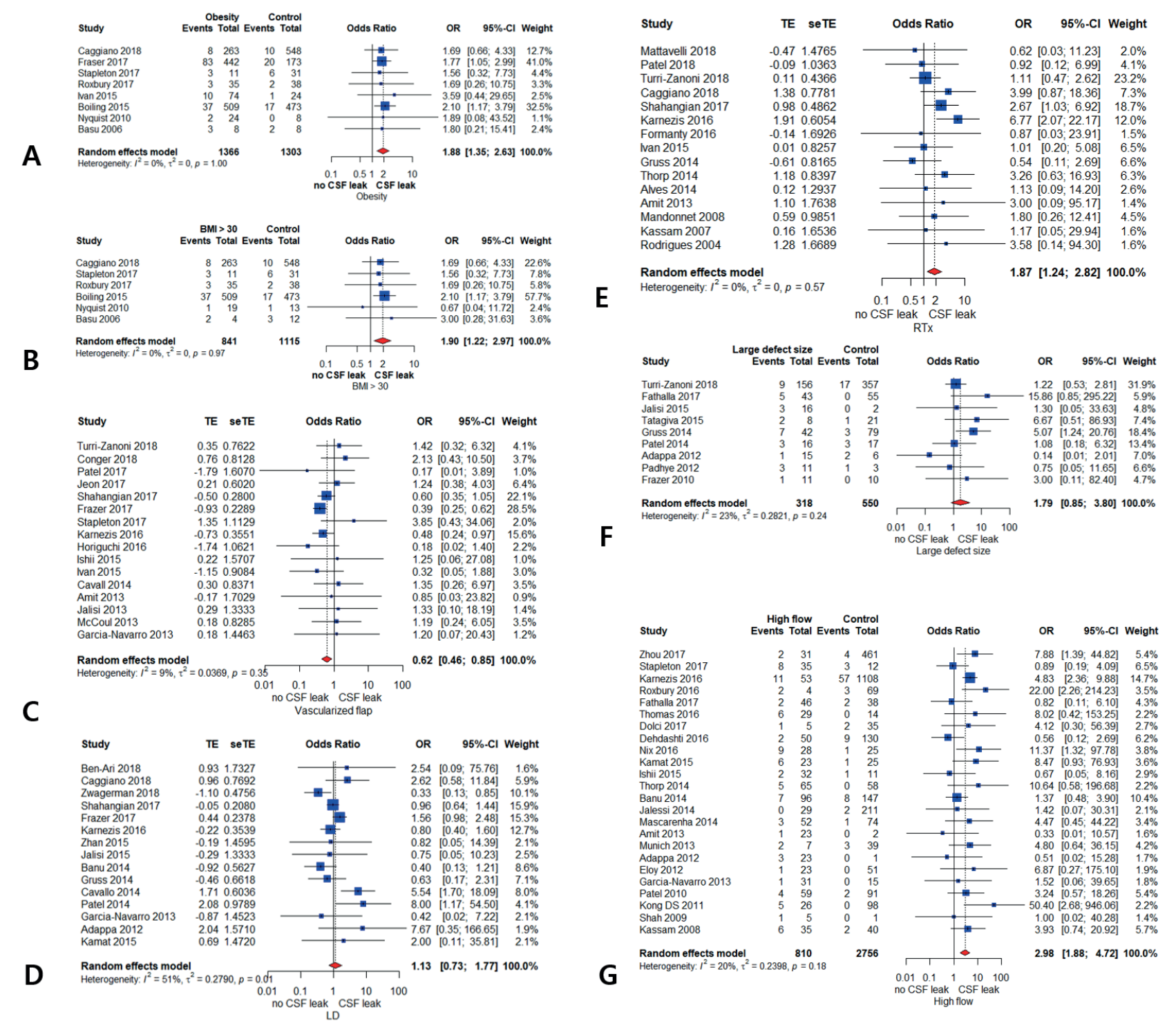

Figure 3. Forest plot of postoperative CSF leakage for each factor. A) Overweight and obesity with BMI over 25; B) obesity subgroup with BMI over 30; C) pedicled vascularized flap; D) lumbar drain; E) perioperative radiotherapy; F) defect size; G) high/low intraoperative flow rate.

(Figure 3D). Egger's regression test did not detect any significant evidence of publication bias ( $p=0.59$ ). Using a funnel plot, most studies were distributed in the center and top portion of the plot, indicating little publication bias (Figure 4E). There was no difference in OR when using Duval and Tweedie's trim and fill method (Figure 4F) (1.01 [95\% Cl, 0.64 to $1.59, \mathrm{p}=0.97]$ ).

\section{History of perioperative radiotherapy}

Fifteen studies regarding perioperative radiotherapy with a total sample of 4,028 patients were included. Analysis of CSF leakage across perioperative radiotherapy revealed an odds ratio of 1.87 [ $95 \% \mathrm{Cl}, 1.24$ to $2.82, \mathrm{p}=0.002$ ] with no heterogeneity $(\mathrm{I} 2=0 \%)$ (Figure 3E). Egger's regression test detected no significant evidence of publication bias ( $p=0.58$ ). Using a funnel plot, most studies were distributed in the center and top of the plot, indi- cating little publication bias (Figure 4G). When using Duval and Tweedie's trim and fill method, there was no significant difference in OR (Figure 4H) (OR: 2.21 [95\% Cl, 1.51 to 3.26, $p<0.01]$ ).

\section{Defect size}

Nine studies regarding defect size with a total sample of 355 patients were included. Analysis of CSF leakage across defect size revealed an odds ratio of 1.79 [ $95 \% \mathrm{Cl}, 0.85$ to $3.80, \mathrm{p}=0.13]$ with low heterogeneity ( $12=23 \%)$ (Figure 3F). Egger's regression test was not performed due to the low sample size. Using a funnel plot, most studies showed an even distribution over the entire plot (Figure 4I). When using Duval and Tweedie's trim and fill method, there was no difference in OR (Figure 4J) (OR: 1.56 [95\% $\mathrm{Cl}, 0.71$ to $3.43, \mathrm{p}=0.27]$ ). 


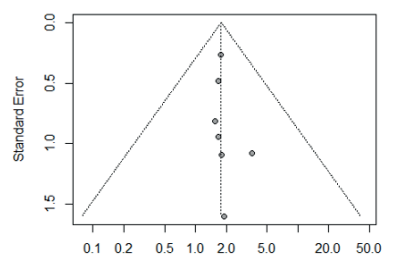

A
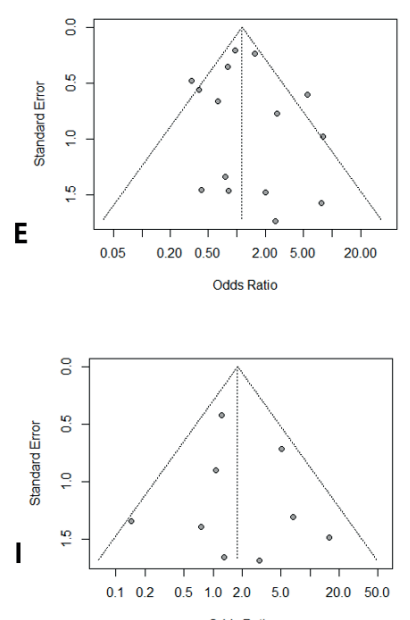

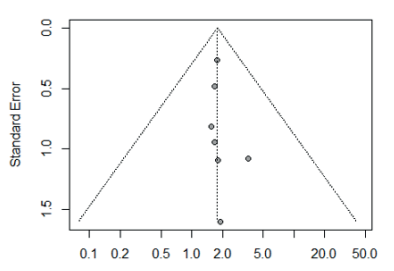

Odds Ratio

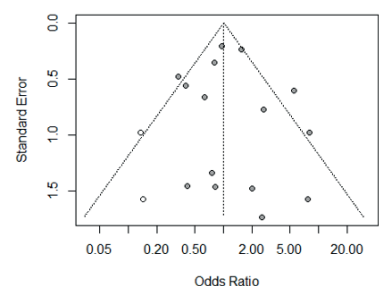

Odds Ratio

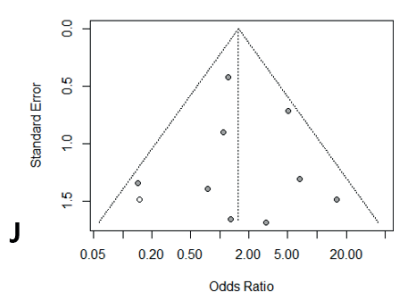

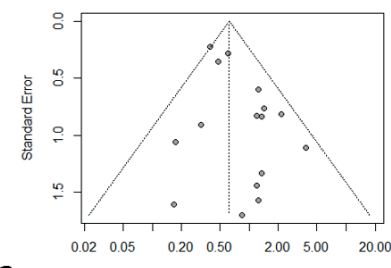

C

Odds Ratio

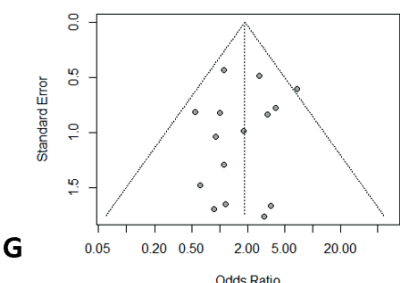

H

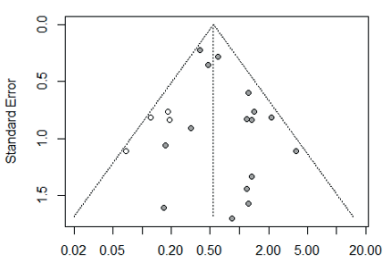

D

Odds Ratio

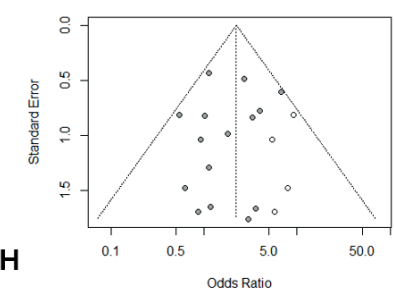

L

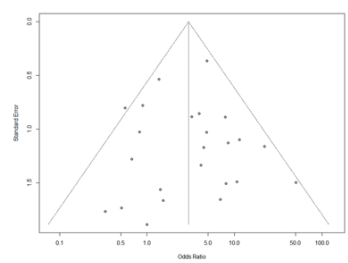

Figure 4. Funnel plots to indicate publication bias and their correction using Duval and Tweedie's trim and fill method to adjust for potentially unpublished reports. A) Obesity; B) obesity after correction using Duval and Tweedie's trim and fill method; C) vascularized pedicled flap; D) vascularized pedicled flap after correction using Duval and Tweedie's trim and fill method; E) lumbar drain; F) lumbar drain after correction using Duval and Tweedie's trim and fill method; $\mathrm{G}$ ) radiotherapy; $\mathrm{H}$ ) radiotherapy after correction using Duval and Tweedie's trim and fill method; I) defect size; J) defect size after correction using Duval and Tweedie's trim and fill method; $K$ ) intraoperative flow rate; $L$ ) intraoperative flow rate after correction using Duval and Tweedie's trim and fill method.

\section{High flow vs. Low flow}

Twenty four studies concerning CSF pressure with a total sample of 3566 patients were included. Analysis of CSF leakage across high flow rates revealed an odds ratio of $2.98[95 \% \mathrm{Cl}, 1.88$ to $4.72, p<0.01]$ with low heterogeneity $(I 2=20.4 \%)$ (Figure $3 G)$. Egger's regression test detected no significant evidence of publication bias $(p=0.28)$. Using a funnel plot, most studies showed an even distribution over the entire plot, indicating little publication bias (Figure 4K). There was no significant difference in OR when using Duval and Tweedie's trim and fill method (Figure $4 \mathrm{~L}$ ) (OR: 2.98 [95\% Cl, 1.88 to $4.72, \mathrm{p}<0.01]$ ).

\section{Discussion}

Postoperative CSF leakage remains a major cause of morbidity in endoscopic endonasal skull base surgery. Identifying the risk factors is important when performing reconstructions and consulting patients. However, there is little published data dealing with this.

CSF leakage can largely be divided into spontaneous and secondary causes. Among these, we have focused only on postoperative CSF leakage that occurred after skull base tumor surgery because spontaneous leakage is rare and has a unique pathophysiology that is different from that in tumor cases.

A total of 56 studies showed that the rate of postoperative CSF leakage after endonasal skull base surgery was $7.2 \%$. This finding is presented as a whole, regardless of patient weight, radiation history, tumor size, and lumbar drain placement. The percentage of postoperative CSF leakage, as shown in Figure 2, does not seem to increase or decrease significantly over time, even when compared by year (Figure 2B). Some studies have shown the importance of learning curves in individual centers $(14,62)$, but our data showed that there was no significant improvement with time.

Empty sella syndrome is frequently observed in normal obese people, and elevated intracranial pressure may be the underlying mechanism ${ }^{(63)}$. This obesity has been confirmed in individual studies where there is not only increased probability of spontaneous CSF leakage but also increased probability of postoperative CSF leakage in skull base procedures ${ }^{(60)}$.

The vascularized flaps used included the middle turbinate flap, inferior turbinate flap, pericranial flap, nasoseptal flap (NSF), etc. A free tissue graft such as fascia or fat required about 7 days for 
neovascularization and sometimes some portion of the graft material would be necrotized. On the other hand, a vascularized flap can quickly progress to the vascularization phase and rarely become necrotic. Therefore, it is reasonable that a vascularized flap can have a better outcome when reconstructing a skull base defect. The vascularized flap is usually only used in CSF leakage with a high flow rate, so we excluded pituitary surgery for this comparison because of selection bias. Because there is usually no intraoperative CSF leakage or low flow CSF leakage in pituitary surgery, a free graft is usually used and inevitably, low postoperative CSF leakage is encountered. As a result, with the exception of pituitary adenoma, the use of a vascularized flap reduced postoperative CSF leakage by a factor of 0.62 compared to a free graft (Figure 3C).

There is a debate regarding the effect of lumbar drainage (LD) on postoperative CSF leakage. Cavallo et al. noted that, in 103 craniopharyngioma cases, LD had no role in reducing postoperative CSF leakage ${ }^{(43)}$. Caggiano et al., analyzing 811 cases of endonasal skull base surgical procedures, found that LD did not have much effect in preventing postoperative CSF leakage ${ }^{(17)}$. However, a recent RCT reported that LD reduced postoperative CSF leakage (LD vs. no LD: $8.2 \%$ vs $21.2 \%)^{(4)}$. In our meta-analysis, the OR of LD was 1.13 with moderate heterogeneity $(I 2=51 \%$, $\mathrm{p}=0.41$ ). There was little publication bias and the result was quite convincing. However, surgeons tend to perform LD in higher risk patients or when the surgeon feels that the reconstruction was not completely successful. So, retrospective studies, whether using LD or not, have their own bias, and meta-analysis using mostly these retrospective studies also show some bias. We have to interpret these results carefully.

Radiation works by damaging the DNA of normal and cancerous tissue ${ }^{(64)}$. Although Intensity-Modulated Radiation Therapy has recently been introduced to prevent damage to surrounding tissue, there is still no guarantee that radioactive beams will not encroach on that tissue. Therefore, radiation is likely to damage normal tissue around the tumor, and so there may be more CSF leakage in patients with a history of radiation therapy. In our results, patients who received radiation therapy were 1.87 times more likely to have postoperative CSF leakage.

There has been controversy about whether a larger defect size could increase the possibility of CSF leakage after endoscopic skull base surgery. Our results showed that larger defect sizes did not increase postoperative CSF leakage $(p=0.13)$. However, a higher flow rate could lead to more CSF leakage (Figure 3l; OR: $2.98, p<0.01$ ). The results for this high flow rate have little publication bias, indicating that the results are robust and more reliable.

There are several limitations in our study. First, histologic factors and surgical approach methods were not considered in our study. Because not all studies included data on the surgical approach or histologic factors for all individuals, the final results of our meta-analysis cannot be complete without the data for all these individuals. Second, due to the lack of RCTs, the results of our study may be less persuasive than results originating from purely RCTs. In the future, further studies from RCTs can enrich and substantiate our results.

Despite these limitations, this is the first known meta-analysis regarding the risk factors for postoperative CSF leakage after endonasal endoscopic skull base surgery. This study could provide important information for the endoscopic skull base surgeon who manages and counsels a diverse group of patients who may be undergoing this surgical procedure.

\section{Conclusion}

The risk factors for postoperative CSF leakage after endonasal endoscopic skull base surgery are obesity, perioperative radiotherapy, high intraoperative CSF pressure and free grafts. However, CSF diversion and defect size were not significant risk factors in this meta-analysis. Further prospective studies could validate our data.

\section{Acknowledgements}

None.

\section{Authorship contribution}

Acquisition of data: JSK, SDH; analysis and interpretation of data: JSK, SDH; drafting the manuscript for critical intellectual content: JSK, SDH; review and improvement of the manuscript: $\mathrm{SDH}$; conception and design of the study: JSK, SDH.

\section{Conflict of interest}

None.

\section{References}

1. Schaefer SD, Manning S, Close LG. Endoscopic paranasal sinus surgery: indications and considerations. Laryngoscope 1989; 99: 1-5.

2. Ivan ME, lorgulescu JB, El-Sayed I, et al. Risk factors for postoperative cerebrospinal fluid leak and meningitis after expanded endoscopic endonasal surgery. J Clin Neurosci 2015; 22: 48-54

3. Fraser S, Gardner PA, Koutourousiou M, et al
Risk factors associated with postoperative cerebrospinal fluid leak after endoscopic endonasal skull base surgery. J Neurosurg 2018; 128: 1066-1071.

4. Zwagerman NT, Wang EW, Shin SS, et al Does lumbar drainage reduce postoperative cerebrospinal fluid leak after endoscopic endonasal skull base surgery? A prospective, randomized controlled trial. J Neurosurg 2018: 1-7.

5. Jalisi S, O'Gara B, Toshkezi G, Chin L. Local vascularized flap reconstruction of the skull base-clinical outcomes and analysis. World Neurosurg 2015; 83: 87-92.

6. Turri-Zanoni M, Zocchi J, Lambertoni A, et al. endoscopic endonasal reconstruction of anterior skull base defects: What factors really affect the outcomes? World Neurosurg 2018; 116: e436-e443.

7. Adappa ND, Learned KO, Palmer JN, Newman JG, Lee JY. Radiographic enhancement of the nasoseptal flap does not pre- 
dict postoperative cerebrospinal fluid leaks in endoscopic skull base reconstruction. Laryngoscope 2012; 122: 1226-1234.

8. Garcia-Navarro V, Anand VK, Schwartz TH. Gasket seal closure for extended endonasal endoscopic skull base surgery: efficacy in a large case series. World Neurosurg 2013; 80: 563-568.

9. Stapleton AL, Tyler-Kabara EC, Gardner PA, Snyderman $\mathrm{CH}$, Wang EW. Risk factors for cerebrospinal fluid leak in pediatric patients undergoing endoscopic endonasal skull base surgery. Int J Pediatr Otorhinolaryngol 2017; 93: 163-166.

10. Conger A, Zhao F, Wang $X$, et al. Evolution of the graded repair of CSF leaks and skull base defects in endonasal endoscopic tumor surgery: trends in repair failure and meningitis rates in 509 patients. J Neurosurg 2018; 130: 861-875.

11. Liberati A, Altman DG, Tetzlaff J, et al. The PRISMA statement for reporting systematic reviews and meta-analyses of studies that evaluate health care interventions: explanation and elaboration. PLoS Med 2009; 6: e1000100.

12. Egger M, Davey Smith G, Schneider M, Minder C. Bias in meta-analysis detected by a simple, graphical test. BMJ 1997; 315: 629-634.

13. Duval S, Tweedie R. Trim and fill: A simple funnel-plot-based method of testing and adjusting for publication bias in meta-analysis. Biometrics 2000; 56: 455-463.

14. Fraser S, Gardner PA, Koutourousiou M, et al, Risk factors associated with postoperative cerebrospinal fluid leak after endoscopic endonasal skull base surgery. J Neurosurg 2017: 1-6.

15. Rotman $L E$, Kicielinski KP, Broadwater DR, et al. Predictors of nasoseptal flap use after endoscopic transsphenoidal pituitary mass resection. World Neurosurg. 2019, 124: e356-e364.

16. Kuan EC, Yoo F, Patel PB, Su BM, Bergsneider $M$, Wang MB. An algorithm for sellar reconstruction following the endoscopic endonasal approach: A review of 300 consecutive cases. J Neurol Surg B Skull Base 2018; 79: 177-183.

17. Caggiano C, Penn DL, Laws ER, Jr. The role of the lumbar drain in endoscopic endonasal skull base surgery: A retrospective analysis of 811 cases. World Neurosurg 2018; 117: e575-e579.

18. Ben-Ari O, Wengier A, Ringel B, et al. Nasoseptal flap for skull base reconstruction in children. J Neurol Surg B Skull Base 2018; 79: 37-41

19. Patel PN, Stafford AM, Patrinely JR, et al. Risk factors for intraoperative and postoperative cerebrospinal fluid leaks in endoscopic transsphenoidal sellar surgery. Otolaryngol Head Neck Surg 2018; 158: 952-960.

20. Kutlay M, Durmaz A, Ozer I, et al. Extended endoscopic endonasal approach to the ventral skull base lesions. Clin Neurol Neurosurg 2018; 167: 129-140.
21. Mattavelli D, Schreiber A, Villaret AB, et al. Complications and donor site morbidity of 3-layer reconstruction with iliotibial tract of the anterior skull base: Retrospective analysis of 186 patients. Head Neck 2018; 40: 63-69.

22. Jeon C, Hong SD, Seol HJ, et al. Reconstructive outcome of intraoperative cerebrospinal fluid leak after endoscopic endonasal surgery for tumors involving skull base. J Clin Neurosci 2017; 45: 227-231.

23. Patel VS, Thamboo A, Quon J, et al. Outcomes after endoscopic endonasal resection of craniopharyngiomas in the pediatric population. World Neurosurg 2017; 108: 6-14.

24. Shahangian A, Soler ZM, Baker A, et al. Successful repair of intraoperative cerebrospinal fluid leaks improves outcomes in endoscopic skull base surgery. Int Forum Allergy Rhinol 2017; 7: 80-86.

25. Fathalla H, Di leva A, Lee J, et al. Cerebrospinal fluid leaks in extended endoscopic transsphenoidal surgery: covering all the angles. Neurosurg Rev 2017; 40: 309318.

26. Dolci RLL, Miyake MM, Tateno DA, et al. Postoperative otorhinolaryngologic complications in transnasal endoscopic surgery to access the skull base. Braz $J$ Otorhinolaryngol 2017; 83: 349-355.

27. Karnezis TT, Baker AB, Soler ZM, et al. Factors impacting cerebrospinal fluid leak rates in endoscopic sellar surgery. Int Forum Allergy Rhinol 2016; 6: 1117-1125.

28. Roxbury CR, Saavedra T, Ramanathan M Jr., et al. Layered sellar reconstruction with avascular free grafts: Acceptable alternative to the nasoseptal flap for repair of lowvolume intraoperative cerebrospinal fluid leak. Am J Rhinol Allergy 2016; 30: 367-371.

29. Thomas R, Chacko AG. Principles in skull base reconstruction following expanded endoscopic approaches. J Neurol Surg B Skull Base 2016; 77: 358-363.

30. Dehdashti AR, Stofko D, Okun J, Obourn C, Kennedy T. Endoscopic endonasal reconstruction of skull base: repair protocol. J Neurol Surg B Skull Base 2016; 77: 271-278.

31. Nix P, Tyagi A, Phillips N. Retrospective analysis of anterior skull base CSF leaks and endoscopic repairs at Leeds. Br J Neurosurg 2016; 30: 422-426

32. Horiguchi $\mathrm{K}$, Nishioka $\mathrm{H}$, Fukuhara $\mathrm{N}$, Yamaguchi-Okada M, Yamada S. A new multilayer reconstruction using nasal septal flap combined with fascia graft dural suturing for high-flow cerebrospinal fluid leak after endoscopic endonasal surgery. Neurosurg Rev 2016; 39: 419-427.

33. Fonmarty $\mathrm{D}$, Bastier $\mathrm{PL}$, Lechot $\mathrm{A}$, Gimbert E, de Gabory L. Assessment of abdominal fat graft to repair anterior skull base after malignant sinonasal tumor extirpation. Otolaryngol Head Neck Surg 2016; 154: 540-546.

34. Boling CC, Karnezis TT, Baker AB, et al. Multiinstitutional study of risk factors for peri- operative morbidity following transnasal endoscopic pituitary adenoma surgery. Int Forum Allergy Rhinol 2016; 6: 101-107.

35. Tatagiba M, Rigante L, Mesquita Filho P, Ebner FH, Roser F. Endoscopic-assisted posterior intradural petrous apicectomy in petroclival meningiomas: A clinical series and assessment of perioperative morbidity. World Neurosurg 2015; 84: 1708-1718.

36. Zhan R, Chen S, Xu S, Liu JK, Li X. Postoperative low-flow cerebrospinal fluid leak of endoscopic endonasal transsphenoidal surgery for pituitary adenoma--Wait and see, or lumbar drain? J Craniofac Surg 2015; 26: 1261-1264.

37. Kamat A, Lee JY, Goldstein GH, et al. Reconstructive challenges in the extended endoscopic transclival approach. J Laryngol Otol 2015; 129: 468-472.

38. Ishii Y, Tahara S, Hattori Y, Teramoto A, Morita A, Matsuno A. Fascia patchwork closure for endoscopic endonasal skull base surgery. Neurosurg Rev 2015; 38: 551-556; discussion 556-557.

39. Alves MV, Roberts D, Levine NB, DeMonte F, Hanna EY, Kupferman ME. Impact of chemoradiotherapy on CSF leak repair after skull base surgery. J Neurol Surg B Skull Base 2014; 75: 354-357.

40. Thorp BD, Sreenath SB, Ebert CS, Zanation AM. Endoscopic skull base reconstruction: a review and clinical case series of 152 vascularized flaps used for surgical skull base defects in the setting of intraoperative cerebrospinal fluid leak. Neurosurg Focus 2014; 37: E4.

41. Banu MA, Szentirmai O, Mascarenhas L, Salek AA, Anand VK, Schwartz TH. Pneumocephalus patterns following endonasal endoscopic skull base surgery as predictors of postoperative CSF leaks. J Neurosurg 2014; 121: 961-975.

42. Gruss CL, Al Komser M, Aghi MK, et al. Risk factors for cerebrospinal leak after endoscopic skull base reconstruction with nasoseptal flap. Otolaryngol Head Neck Surg 2014; 151: 516-521.

43. Cavallo LM, Frank G, Cappabianca P, et al. The endoscopic endonasal approach for the management of craniopharyngiomas: a series of 103 patients. J Neurosurg 2014; 121: 100-113.

44. Patel R, Buchmann LO, Hunt J. The use of the temporoparietal fascial flap in preventing CSF leak after lateral skull base surgery. J Neurol Surg B Skull Base 2013; 74: 311-316.

45. Mascarenhas L, Moshel YA, Bayad F, et al. The transplanum transtuberculum approaches for suprasellar and sellarsuprasellar lesions: avoidance of cerebrospinal fluid leak and lessons learned. World Neurosurg 2014; 82: 186-195.

46. Amit M, Margalit N, Abergel A, Gil Z. Fascia lata for endoscopic reconstruction of highflow leaks: the champagne cork technique. Otolaryngol Head Neck Surg 2013; 148: 697-700.

47. Eloy JA, Patel AA, Shukla PA, Choudhry OJ, 
Liu JK. Early harvesting of the vascularized pedicled nasoseptal flap during endoscopic skull base surgery. Am J Otolaryngol 2013; 34: 188-194.

48. Munich SA, Fenstermaker RA, Fabiano AJ, Rigual NR. Cranial base repair with combined vascularized nasal septal flap and autologous tissue graft following expanded endonasal endoscopic neurosurgery. Neurol Surg A Cent Eur Neurosurg 2013; 74: 101-108.

49. McCoul ED, Anand VK, Singh A, Nyquist GG, Schaberg MR, Schwartz TH. Long-term effectiveness of a reconstructive protocol using the nasoseptal flap after endoscopic skull base surgery. World Neurosurg 2014; 81: 136-143.

50. Padhye $\mathrm{V}$, Naidoo $\mathrm{Y}$, Alexander $\mathrm{H}$, et al. Endoscopic endonasal resection of anterior skull base meningiomas. Otolaryngol Head Neck Surg 2012; 147: 575-582.

51. Eloy JA, Kuperan AB, Choudhry OJ Harirchian S, Liu JK. Efficacy of the pedicled nasoseptal flap without cerebrospinal fluid (CSF) diversion for repair of skull base defects: incidence of postoperative CSF leaks. Int Forum Allergy Rhinol 2012; 2: 397-401.

52. Kong DS, Kim HY, Kim SH, et al. Challenging reconstructive techniques for skull base defect following endoscopic endonasal approaches. Acta Neurochir (Wien) 2011; 153: 807-813

53. Patel MR, Stadler ME, Snyderman $\mathrm{CH}$, et al. How to choose? Endoscopic skull base reconstructive options and limitations. Skul Base 2010; 20: 397-404.
54. Horiguchi K, Murai H, Hasegawa $Y$ Hanazawa T, Yamakami I, Saeki N. Endoscopic endonasal skull base reconstruction using a nasal septal flap: surgical results and comparison with previous reconstructions. Neurosurg Rev 2010; 33 235-241; discussion 241

55. Nyquist GG, Anand VK, Mehra S, Kacker A Schwartz TH. Endoscopic endonasal repair of anterior skull base non-traumatic cerebrospinal fluid leaks, meningoceles, and encephaloceles. J Neurosurg 2010; 113: 961-966.

56. Shah RN, Surowitz JB, Patel MR, et al Endoscopic pedicled nasoseptal flap reconstruction for pediatric skull base defects. Laryngoscope 2009; 119: 1067-1075.

57. El-Banhawy OA, Halaka AN, Altuwaijri MA, Ayad H, El-Sharnoby MM. Long-term outcome of endonasal endoscopic skull base reconstruction with nasal turbinate graft. Skull Base 2008; 18: 297-308

58. Kassam AB, Thomas A, Carrau RL, et al. Endoscopic reconstruction of the cranial base using a pedicled nasoseptal flap. Neurosurgery 2008; 63: ONS44-52; discussion ONS52-43

59. Mandonnet E, Kolb F, Tran Ba Huy P, George B. Spectrum of skull base tumors in children and adolescents: a series of 42 patients and review of the literature. Childs Nerv Syst 2008; 24: 699-706

60. Basu D, Haughey BH, Hartman JM Determinants of success in endoscopic cerebrospinal fluid leak repair. Otolaryngol Head Neck Surg 2006; 135: 769-773.

61. Rodrigues M, O'Malley B W, Jr., Staecker H,
Tamargo R. Extended pericranial flap and bone graft reconstruction in anterior skul base surgery. Otolaryngol Head Neck Surg 2004; 131: 69-76.

62. Kshettry VR, Do H, Elshazly K, et al. The learning curve in endoscopic endonasal resection of craniopharyngiomas. Neurosurg Focus 2016; 41: E9.

63. Schlosser RJ, Bolger WE. Spontaneous nasal cerebrospinal fluid leaks and empty sella syndrome: a clinical association. Am $J$ Rhinol 2003; 17: 91-96.

64. Bomford CK, Kunkler IH, Walter J. Walter and Miller's textbook of radiation therapy. 6th ed. Edinburgh: Churchill Livingstone, 2008.

Sang Duk Hong, MD

Department of Otorhinolaryngology

Head and Neck Surgery

Samsung Medical Center

Sungkyunkwan University School of

Medicine

81 Irwon-ro, Gangnam-gu

Seoul 06351

Korea

Tel: $+82-2-3410-3579$

Fax: +82-2-3410-3879

E-mail:kkam97@gmail.com 